Research Article

\title{
Diagnostic value of fine needle aspiration biopsy in parotid gland neoplasm
}

\author{
Yakup Yegin, Mustafa Çelik*, Burak Olgun, Baver Maşallah Şimsek, Fatma Tülin Kayhan
}

\begin{abstract}
Department of Otorhinolaryngology-Head and Neck Surgery, Bakırköy Dr.Sadi Konuk, Training and Research Hospital, Istanbul, Turkey
\end{abstract}

Received: 25 February 2016

Accepted: 27 March 2016

\section{*Correspondence:}

Dr. Mustafa Çelik,

E-mail:dr.mcelik@yahoo.com

Copyright: ( ) the author(s), publisher and licensee Medip Academy. This is an open-access article distributed under the terms of the Creative Commons Attribution Non-Commercial License, which permits unrestricted non-commercial use, distribution, and reproduction in any medium, provided the original work is properly cited.

\section{ABSTRACT}

Background: The value of fine needle aspiration biopsy (FNAB) in the diagnosis of parotid masses remains unclear, considering current literature. The surgical procedure is not planned according to the FNAB results by the majority of the otorhinolaryngologists. Objectives of the study was to compare the results of FNAB and histopathological results in diagnosing malignancy and benign lesions of parotid gland and to determine the sensitivity, specificity and accuracy of FNAB.

Methods: It is a retrospective clinical chart review study. In total, 61 patients (28 females and 33 males; average age, $46.31 \pm 15.79$ years; age range: 12-82 years) with parotid gland masses who underwent preoperative FNAB were included in this study. All patients underwent FNAB under ultrasound guidance following clinical examination. Histopathological results of the surgical specimens and preoperative results of FNAB were compared and, the sensitivity, specify, positive predictive value (PPV), negative predictive value (NPV), the diagnostic accuracy of FNAB was calculated. A P-value $<0.05$ was considered to reflect statistical significance.

Results: The specificity of FNAB was $100 \%$ and its sensitivity was $57.2 \%$. Accuracy for benign lesion was $91.4 \%$, accuracy for a malignancy was $42.8 \%$ and overall diagnostic accuracy was $92.0 \%$, respectively. PPV for benign lesion was $91.4 \%$ and the NPV was $100 \%$, respectively. PPV for malignancy was $100 \%$ and the NPV was $91.4 \%$, respectively.

Conclusions: We suggest that FNAB is a valid, safe, easy-to-use method for identifying of parotid gland neoplasms. We recommend FNAB for all potential surgical patients. In our opinion, good collaboration between the Otorhinolaryngologist and the pathologist provides the best results.

Keywords: Fine-needle aspiration, Parotid neoplasm, Preoperative, Negative results

\section{INTRODUCTION}

The salivary gland system includes major and several minor glands. Major salivary glands are consist of parotid, submandibular and sublingual glands and also, many minor glands occur in sub-mucosa of the oral cavity such as floor of mouth, gingiva, hard and soft palate, tongue and oropharynx. Salivary gland tumours constitute less than $3 \%$ of all head and neck tumors, despite the potential to occur at every site in the salivary gland. The most common location, as reported in the literature is on the parotid gland. ${ }^{1-3}$ The salivary gland tumours are usually encountered clinical problems. In the literature, there is inconstancy between the time the tumour is first noticed by the patient and when it is presented to the physician. For example, sialadenoma papilliferum is a benign, exophytic, slow-growing, painless tumour of minor salivary gland. The patient described in the study by Abrams and Finck had the tumour for 10 to 12 years prior to presentation. Therefore, the majority of these tumours are benign., Management of these tumour remains unclear. Also, 
management of salivary gland tumours differs from surgeon to surgeon. Suspicion for malignancy in parotid masses usually withstands a correlation between clinical indications and patient's history. Unfortunately, the correct diagnosis of malignancy cannot be predicted considering only a single factor. Also, diagnostic tests seem to be very significant in management of parotid neoplasms. ${ }^{1}$ Three diagnostic tests are recommended to definitively diagnose a tumour as benign or malignancy. The first diagnostic test is fine-needle aspiration biopsy (FNAB). FNAB has used widespread popularity in the field of otorhinolaryngology, especially in the diagnosis of thyroid and neck masses. ${ }^{3-5}$ However, its uses in the diagnosis of parotid gland tumours has generally not been accepted. In the literature, there is no consensus on diagnosis of parotid gland tumours preoperatively. In study of Batsakis et al preoperative FNAB was not necessary for management of parotid mass considering required surgery in most parotid masses. ${ }^{4}$ However, some authors recommended preoperative FNAB for management of parotid masses. ${ }^{6-9}$ Also, it has some advantages and disadvantages. Low risk of complications and performing in the outpatient, minimal recovery time are important advantages of this procedure. ${ }^{10,11}$ However, the most potential disadvantage of this procedure is that it has a wide variation on sensitivity and specificity in differential diagnosis of malignancy and benign lesions. $^{10,13}$ Therefore, in literature, high rates of non-diagnostic results have been reported. An ultrasound guided core biopsy and open excisional biopsy are recommended as second and third option of diagnostic test.

In the present study, we compared the results of FNAB and histopathological in diagnosing malignancy and benign lesions of parotid gland and determined the sensitivity and specificity of FNAB.

\section{METHODS}

We retrospectively reviewed data collected from January 2010 to September 2014 on patients treated in the Department of Otolaryngology, Head and Neck Surgery, of our hospital. In total, 61 patients with parotid gland masses who underwent preoperative FNAB were included in this study. All patients were informed about the study and a written consent was obtained from each patient or parents of the patients. The study protocol was approved by the institutional ethics committee. The study was conducted in accordance with the principles of Helsinki declaration. Otorhinolaryngological and further systemic examination was performed before FNAB. All patients underwent FNAB under ultrasound guidance following clinical examination. In our hospital, all of FNAB were performed by the same radiologist under US-guidance (with the use of a 25 gauge needle). All specimens were examined by the same pathologist. FNAB cytological materials were fixed in alcohol for hematoxylin eosin stain $(\mathrm{H}$ and $\mathrm{E})$. Preoperative cytological findings of FNAB were divided into three groups as follows benign, non-diagnostic and malignant. According to results of FNAB, all surgical procedures were performed by the same otorhinolaryngologist. All patients were followed up at our clinic for at least 12 months after surgery. All surgical specimens were fixed in $10 \%$ neutral buffered formalin for $\mathrm{H}$ and $\mathrm{E}$ stain. Histopathological results of the surgical specimens and preoperative results of FNAB were compared and, the sensitivity, specificity, positive predictive value (PPV), negative predictive value (NPV), the diagnostic accuracy of FNAB was calculated.

\section{Statistical analysis}

Number Cruncher Statistical System (NCSS) 2007 software (Kaysville, UT, USA) was used for all statistical analyses. Descriptive statistics (means and standard deviation, medians with interquartile range) were derived. The significance of each intergroup difference was analysed using Student's t-test, and the significance of any difference in median values was explored with the aid of the Mann Whitney U-test. Qualitative data comparisons were performed using the Yates Continuity Correction test. A P-value $<0.05$ was considered to reflect statistical significance.

\section{RESULTS}

We included 61 patients, $28(45.9 \%)$ females and 33 $(54.1 \%)$ males. Their average age was $46.31 \pm 15.79$ years (range: 12-82 years). Parotid masses were defined on 40 right parotids $(65.6 \%)$ and 21 left parotids (34.4\%), respectively. In results of FNAB, benign in 47 patients (77.0\%), non-diagnostic in 11 patients (18.1\%) and malignant in $3(4.9 \%)$ were reported. The FNAB results are summarized in (Table 1).

Table 1: Results of fine needle aspiration biopsy of the parotid gland.

\begin{tabular}{|llll|}
\hline FNAB Diagnosis & $\begin{array}{l}\text { No. of } \\
\text { cases }\end{array}$ & Percentage \\
\hline $\begin{array}{l}\text { Pleomorphic } \\
\text { adenoma }\end{array}$ & 34 & $55.7 \%$ & \\
\cline { 1 - 2 } Warthin's tumour & 13 & $21.3 \%$ & $\begin{array}{l}\text { Benign } \\
\text { lesions }\end{array}$ \\
\hline $\begin{array}{l}\text { Mucoepidermoid } \\
\text { carcinoma }\end{array}$ & 3 & $4.9 \%$ & \\
\hline Non-diagnostic & 11 & $18.1 \%$ & \\
\hline & 61 & $100 \%$ \\
\hline
\end{tabular}

The histological diagnosis in the study is summarized in (Table 2). The correlation between the FNAB and histopathological results was assessed in 50 patients (Table 3).

The most common histopathological result was benign neoplasm that identified in 51 patients (83.6) and consists of pleomorphic adenoma in 30 patients $(49.2 \%)$ and Whartin's tumour in 13 patients $(21.4 \%)$, respectively. 
Mucoepidermoid carcinoma $(9.8 \%)$ was the most common malignancy, followed by adenocarcinoma $(6.5 \%)$, respectively.

Table 2: Results of histopathological examination of the parotid gland.

\begin{tabular}{|lll|}
\hline Histological diagnosis & No. of cases & Percentage \\
\hline Adenocarcinoma & 4 & $6.5 \%$ \\
\hline Lymphoepithelial cyst & 1 & $1.6 \%$ \\
\hline Lipoma & 2 & $3.3 \%$ \\
\hline Castleman's disease & 1 & $1.6 \%$ \\
\hline $\begin{array}{l}\text { Mucoepidermoid } \\
\text { carcinoma }\end{array}$ & 7 & $11.5 \%$ \\
\hline Oncocytoma & 1 & $1.6 \%$ \\
\hline Pleomorphic adenoma & 30 & $49.2 \%$ \\
\hline Chronic inflammation & 2 & $3.3 \%$ \\
\hline Warthin's tumour & 13 & $21.4 \%$ \\
\hline Total & 61 & $100 \%$ \\
\hline
\end{tabular}

Table 3: Comparison between results of fine needle aspiration biopsy and histopathological examination.

\begin{tabular}{|lll|}
\hline Diagnosis & $\begin{array}{l}\text { FNAB } \\
\text { No. }(\%)\end{array}$ & $\begin{array}{l}\text { Histopathological } \\
\text { No. }(\%)\end{array}$ \\
\hline $\begin{array}{l}\text { Benign/ } \\
\text { inflammatory lesions }\end{array}$ & $\begin{array}{l}4(77 \%) \\
50(81.9 \%)\end{array}$ \\
\hline Malignancy & $3(4.9 \%)$ & $11(18.1 \%)$ \\
\hline Non-diagnostic & $\begin{array}{l}11 \\
(18.1 \%)\end{array}$ & $\begin{array}{l}7(11.5 \%) \\
\text { benign lesions }\end{array}$ \\
\hline & & $4(6.6 \%)$ malignancy \\
\hline
\end{tabular}

Table 4: Summary of studies on the fine needle aspiration biopsy of the parotid gland.

\begin{tabular}{|c|c|c|c|c|}
\hline & $\mathbf{n}$ & $\begin{array}{l}\text { Se } \\
(\%)\end{array}$ & $\begin{array}{l}\text { Sp } \\
(\%)\end{array}$ & $\begin{array}{l}\text { Accuracy } \\
(\%)\end{array}$ \\
\hline Al-Khafaj et al ${ }^{16}$ & 154 & 82 & 86 & 84 \\
\hline Stewart et al ${ }^{17}$ & 341 & 92 & 100 & 98 \\
\hline Zbaren et $\mathrm{al}^{10}$ & 228 & 64 & 95 & 86 \\
\hline Postman et al ${ }^{18}$ & 388 & 88 & 99 & 96 \\
\hline Bajaj et $\mathrm{al}^{14}$ & 69 & 84 & 96 & 94 \\
\hline Seethala et al ${ }^{19}$ & 220 & 86 & 92 & 90 \\
\hline Aversa et $\mathrm{al}^{12}$ & 310 & 83 & 100 & 97 \\
\hline Fakhry et $\mathrm{al}^{20}$ & 202 & 80 & 89.5 & 86.5 \\
\hline Piccioni et al $^{7}$ & 176 & 81 & 99 & 97 \\
\hline Lurie et $\mathrm{al}^{6}$ & 52 & 66 & 100 & 69.2 \\
\hline Lim et $\mathrm{al}^{9}$ & 91 & 80 & 100 & 85.1 \\
\hline Javadi et $\mathrm{al}^{21}$ & 70 & 57.9 & 97.8 & 86 \\
\hline Lee et $\mathrm{al}^{22}$ & 22 & 92.3 & 87.5 & 90.5 \\
\hline Present study & 61 & 57.2 & 100 & 92 \\
\hline
\end{tabular}

Sp- specificity; Se-sensitivity.

The specificity of FNAB was $100 \%$ and its sensitivity was $57.2 \%$. Accuracy for benign lesion was $91.4 \%$, accuracy for a malignancy was $42.8 \%$ and overall diagnostic accuracy was $92.0 \%$, respectively.
PPV for benign lesion was $91.4 \%$ and the NPV was $100 \%$, respectively. PPV for malignancy was $100 \%$ and the NPV was $91.4 \%$, respectively.

Table 5: The histopathological examinations of nondiagnostic results of FNAB.

\begin{tabular}{|ll|}
\hline Patients & Histopathological diagnosis \\
\hline Male, 42 years & Adenocarcinoma \\
\hline Male, 53 years & Adenocarcinoma \\
\hline Female, 39 years & Adenocarcinoma \\
\hline Female, 41 years & Castleman's disease \\
\hline Female, 48 years & Pleomorphic adenoma \\
\hline Female, 46 years & Pleomorphic adenoma \\
\hline Male, 61 years & Pleomorphic adenoma \\
\hline Male, 42 years & Pleomorphic adenoma \\
\hline Female, 59 years & Chronic inflammation \\
\hline Male, 47 years & Mucoepidermoid carcinoma \\
\hline Female, 33 years & Warthin's tumour \\
\hline
\end{tabular}

\section{DISCUSSION}

FNAB is a safe, easy to perform, well tolerated, relatively painless, and inexpensive diagnostic procedure with few complications, such as hemorrhage, facial palsy, acute parotitis and the risk of tumour seeding. ${ }^{11-14}$ The value of FNAB in the diagnosis of parotid masses remains unclear, considering current literature. The surgical procedure is not planned according to the FNAB results by the majority of the otorhinolaryngologists. ${ }^{15,16}$ Some authors recommended that FNAB is an obligatory procedure of the management of parotid tumours, in contrast to others consider that this procedure is not necessary accurate. ${ }^{17-19}$ The most important aim of FNAB is to allocate a malignant tumours from a benign one. Considering preoperative diagnostic information, the otorhinolaryngologist may take into consideration combined or more radical surgical plan for parotidectomy. ${ }^{5}$ According to the WHO 2005 classification of parotid tumours, there are more than 25 different types of malignant tumours, comparing with only nine types of benign tumours have been described. ${ }^{5,6}$ The preoperative FNAB in the case of a malignant result allows:

- Staging,

- Determination of a surgical plan,

- Giving more convenient information to the patient about the surgical plan, risk and complications of surgery such as especially facial palsy. ${ }^{7,8}$

Considering current literature, a sensitivity ranging from 54 to $92 \%$ and a specificity ranging from 86 to $100 \%$ (Table 4). In study of Piccioni et al. ${ }^{7}$ shown that the sensitivity and specificity of FNAB for parotid masses were 81 and $99 \%$, respectively. In study of Lurie et al. ${ }^{6}$ Reported that the sensitivity, specificity and the accuracy of FNAB for parotid masses were 66, 100 and $69.2 \%$ respectively. In study of $\mathrm{Lim}$ et al. $^{9}$ reported that the sensitivity and specificity of FNAB in the diagnosis of 
malignant tumours 80 and $100 \%$, respectively. In study of Zbaren et al. ${ }^{10}$ Shown that the sensitivity, specificity, PPV, NPV and the accuracy of FNAB for parotid masses were $64,95,83,87$ and $86 \%$, respectively. In study of Stow et al. ${ }^{11}$ Reported that the sensitivity, specificity and accuracy in their series were 86.9, 96.3 and $92.3 \%$, respectively. In the Aversa's study, the sensitivity was $83 \%$, the specificity and the accuracy were reported as 100 and $97 \%$, respectively. ${ }^{12}$ In the present study, the sensitivity and specificity were $57.2 \%$ and $100 \%$, respectively, consistent with the relevant literature. In 2011, a meta-analysis established also an estimated global sensitivity of $80 \%$ and an estimated specificity of $97 \% .^{13}$ No published study has reported a sensitivity of FNAB higher than $92 \%$. This low sensitivity can be attributable to the high false negative rate for the diagnosis of malignancy, as the malignant tumours were falsely diagnosed as benign in 8 to $49 \%$ of cases depending on the series. ${ }^{7-12}$ Therefore, malignant tumours can be falsely diagnosed as benign tumours. Also, FNAB can never exclude a malignancy. Diagnosis of parotid mass by FNAB is affected by two significant conditions including non-diagnostic specimen and misdiagnosis. Non-diagnostic specimen is defined as inadequate material obtained for histological diagnosis. Inexperienced pathologist and the variety of cells in specimen can be caused to misdiagnosis. Non-diagnostic and inadequate specimens have been reported in $2-10 \%$ of cases in the literature. ${ }^{10-12}$ In the present study, we observed 11 of $61(18.1 \%)$ non-diagnostic results. The histopathological examinations of non-diagnostic results of FNAB were summarized in (Table 5), in the present study.

The potential reasons that to cause to non-diagnostic results are follow as:

- Inexperienced otorhinolaryngologist who performed FNAB.

- Being necrosis, hemorrhage in the parotid mass.

- Very rigid lesions with low cellularity,

- Taking specimen from small nodules. ${ }^{12-17}$

The potential reasons that caused to misdiagnosis results are follow as:

- Inexperienced pathologist who examined the specimen.

- Atypical cells.

- Chronic reactive sialoadenitis may be connected with several types of malignancy. Therefore, the opposite is possible.

- Diagnosing lymphoma is very difficult, among pathologist experiences. ${ }^{13-21}$

Good collaboration between the otorhinolaryngologist and the pathologist provides the best results. However, in the context of a non-diagnostic FNAB, high suspicion for parotid malignancy may be warranted for otorhinolaryngologist. $^{19-22}$ FNAB under ultrasound guidance has higher sensitivity more than blind FNAB. Bajaj et al and Pratap et al reported that the sensitivity of FNAB was increased by $20 \%$ from to $65 \%$ to $85 \%$, respectively, with using ultrasound guidance. ${ }^{14,15}$ Our clinical praxis has been modified since this study, and now in our clinic, all FNAB were performed by using ultrasound guidance by an expert radiologist.

\section{CONCLUSION}

In conclusion, we suggest that FNAB is a valid, safe, easy-to-use method for identifying of parotid gland neoplasms. We recommend FNAB for all potential surgical patients. In our opinion, good collaboration between the otorhinolaryngologist and the pathologist provides the best results.

\section{Funding: No funding sources}

Conflict of interest: None declared

Ethical approval: The study was approved by the Institutional Ethics Committee

\section{REFERENCES}

1. Liu CC, Jethwa AR, Khariwala SS, Johnson J, Shin JJ. Sensitivity, Specificity, and Posttest Probability of Parotid Fine-Needle Aspiration: A Systematic Review and Meta-analysis. Otolaryngol Head Neck Surg. 2016;154:9-23.

2. Loehn B, Sutton C, Belcher J, Harton A, Anderson D, Walvekar RR. Sialadenoma papilliferum of the parotid gland: case report and review of literature. Head Neck. 2013;35:74-6.

3. Ghanem SA, Cohen O, Lazutkin A, Ghanem YA, Fliss DM, Yehuda M. Evaluation of clinical presentation and referral indications for ultrasoundguided fine needle aspiration biopsy of the thyroid as possible predictors of thyroid cancer. Head Neck. 2015:doi: 10.1002/hed.24143.

4. Batsakis JG, Sueige N, El-Naggar AK. Fine-needle aspiration of salivary glands: its utility and tissue effects. Ann Otol Rhinol Laryngol.1992;101:185-8.

5. Lin AC, Bhattacharyya N. The utility of fine needle aspiration in parotid malignancy. Otolaryngol Head Neck Surg. 2007;136:793-8.

6. Lurie M, Misselevithch I, Fradis M. Diagnostic value of fine needle aspiration from parotid gland lesions. Isr Med Assoc J. 2002;4:681-3.

7. Piccioni LO, Fabiano B, Gemma M, Sarandria D, Bussi M. Fine needle aspiration cytology in the diagnosis of parotid lesions. Acta Otorhinolaryngol Ital. 2011;31:1-4.

8. Zerpa ZV, Gonzáles CMT, Porras AG, Acuña MM, Ferriol EE, Galofre JD. Diagnostic accuracy of fine needle aspiration cytology in parotid tumours. Acta Otorrinolaringol Esp. 2014;65:157-61.

9. Lim CM, They J, Loh KS, Chao SS, Lim LH, Tan LK. Role of fine needle aspiration cytology in the evaluation of parotid tumours. ANZ J Surg. 2007;77:742-4. 
10. Zbaren P, Schar C, Hotz MA, Loosli H. Value of fine needle aspiration cytology of parotid gland masses. Laryngoscope. 2001;111:1989-92.

11. Stow N, Veivers D, Poole A. Fine needle aspiration cytology in the management of salivary gland tumors: an Australian experience. Ear Nose Throat J. 2004;83:128-31.

12. Aversa S, Ondolo C, Bollito E, Fadda G, Conticello S. Preoperative cytology in the management of parotid neoplasms. Am J Otolaryngol. 2006;27:96100.

13. Schmidt RL, Hall BJ, Wilson AR, et al. A systematic review and meta-analysis of the diagnostic accuracy of fine-needle aspiration cytology for parotid gland lesions. Am J Clin Pathol. 2011;136:45-59.

14. Bajaj Y, Singh S, Cozens N, Sharp J. Critical clinical appraisal of the role of ultrasound-guided fine needle aspiration cytology in the management of parotid tumours. J Laryngol Otol. 2005;119:28992.

15. Pratap R, Qayyum A, Ahmed N, Jani P, Berman LH. Ultrasound guided core needle biopsy of parotid gland swellings. J Laryngol Otol. 2009;123:449-52.

16. Khafaji ABM, Nestok BR, Katz RL. Fine needle aspiration of 154 parotid masses with histologic correlation: ten year experience at the University of Texas M. D. Anderson Cancer Center. Cancer.1998;84:153-9.
17. Stewart CJ, MacKenzie K, McGarry GW, et al. Fine needle aspiration cytology of salivary gland: a review of 341 cases. Diagn Cytopathol. 2000;22:139-46.

18. Postema RJ, Velthuysen VML, Brekel VMW, Balm AJ, Peterse JL. Accuracy of fine needle aspiration cytology of salivary gland lesions in The Netherlands Cancer Institute. Head Neck. 2004;26:418-24.

19. Seethala RR, LiVolsi VA, Baloch ZW. Relative accuracy of fine needle aspiration and frozen section in the diagnosis of lesions of the parotid gland. Head Neck. 2005;27:217-23.

20. Fakhry N, Antonini F, Michel J, Penicaud M, Mancini J, Lagier A, et al. Fine needle aspiration cytology in the management of parotid masses: evaluation of 249 patients. Eur Ann Otorhinolaryngol Head Neck Dis. 2012;129:131-5.

21. Javadi M, Asghari A, Hassannia F. Value of fine needle aspiration cytology in the evaluation of parotid tumors. Indian J Otolaryngol Head Neck Surg. 2012;64:257-60.

22. Lee DH, Yoon TM, Lee JK, Lim SC. Clinical utility of fine needle aspiration cytology in pediatric parotid tumors. Int $\mathbf{J}$ Pediatr Otorhinolaryngol. 2013;77:1272-5.

Cite this article as: Yegin $\mathrm{Y}$, Çelik M, Olgun B, Şimsek BM, Kayhan FT. Diagnostic value of fine needle aspiration biopsy in parotid gland neoplasm. Int J Otorhinolaryngol Head Neck Surg 2016;2:5660. 